\title{
Circadian Clock, Time-Restricted Feeding and Reproduction
}

\author{
Xiaoyue Pan ${ }^{1,2, *}$, Meredith J. Taylor ${ }^{1,2}$, Emma Cohen ${ }^{2}$, Nazeeh Hanna ${ }^{1,3}$ and \\ Samantha Mota ${ }^{1,2}$ (D) \\ 1 Department of Foundations of Medicine, New York University Long Island School of Medicine, Mineola, \\ New York, NY 11501, USA; merriet@verizon.net (M.J.T.); Nazeeh.Hanna@nyulangone.org (N.H.); \\ Samantha.Mota@nyulangone.org (S.N.) \\ 2 Diabetes and Obesity Research Center, NYU Winthrop Hospital, Mineola, New York, NY 11501, USA; \\ ecohen@udel.edu \\ 3 Department of Pediatrics, NYU Winthrop Hospital, Mineola, New York, NY 11501, USA \\ * Correspondence: Xiaoyue.pan@nyulangone.org
}

Received: 21 December 2019; Accepted: 24 January 2020; Published: 28 January 2020

\begin{abstract}
The goal of this review was to seek a better understanding of the function and differential expression of circadian clock genes during the reproductive process. Through a discussion of how the circadian clock is involved in these steps, the identification of new clinical targets for sleep disorder-related diseases, such as reproductive failure, will be elucidated. Here, we focus on recent research findings regarding circadian clock regulation within the reproductive system, shedding new light on circadian rhythm-related problems in women. Discussions on the roles that circadian clock plays in these reproductive processes will help identify new clinical targets for such sleep disorder-related diseases.
\end{abstract}

Keywords: circadian clock; hormone regulation; time-restricted feeding; neural regulation; reproduction; reproductive failure

\section{Introduction}

In mammals, the body's clock is regulated through a series of various genes present in all organs such as Period genes (Per 1/2/3, Period Circadian Regulator1/2/3), Cryptochrome genes (Cry 1/2, Cryptochrome Circadian Regulator 1/2), Circadian Locomotor Output Cycles Kaput (Clock) gene, and Aryl hydrocarbon receptor nuclear translocator-like protein 1 (ARNTL, also known as MOP3 or Bmal1) gene [1-7]. In SCN as well as peripheral tissue, Clock and Bmal1 heterodimerize to activate transcription of circadian target genes, including the genes of Per 1/2/3 and Cry1/2). Per and Cry interact and inhibit Bmal1 and Clock (Figure 1). The rhythmic expression of Clock genes rhythm is present in a wide array of tissues (including the liver, kidney, lung, and heart), and these tissues have their own rhythms distinct from that of the suprachiasmatic nucleus (SCN). SCN's "circadian clock" genes can control behavior, feeding, and reproduction through neurotransmitters and hormones (Figure 1) $[2,8]$. These circadian clock genes drive the body's circadian rhythm, and their disruption can lead to a host of issues such as cancer, obesity, and atherosclerosis [3,9-16]. Disruption of the clock genes has also been implicated in a variety of malfunctions of homeostasis, including glucose, and lipid metabolism [17-20]. Several circadian clock genes such as Clock, Bmal1, Per2, and Cry1 are expressed in human and animal full-term placenta tissue, suggesting a potential circadian rhythm [21-26]. As demonstrated in prior research, the relationships between the placenta and fetal circadian signals are complex and are essential for the development of a successful pregnancy. Based on microarray studies of the liver, kidney, and heart tissues, it was revealed that some of the rhythms are driven directly by clock genes, 
whereas other aspects of these rhythms are induced by other tissue-specific transcription factors that are controlled by clock genes $[24,27,28]$. With the recent discovery that genes such as Clock, Bmal1, Per2, and Cry 1 are also present in the mammalian ovary, oviduct, uterus and placenta, observations have led to the hypothesis that disruption of the body's natural clock has a negative effect on the embryo development and pregnancy [22,24]. Currently, however, there are few studies linking fertility problems to disruption in circadian clock genes in humans.

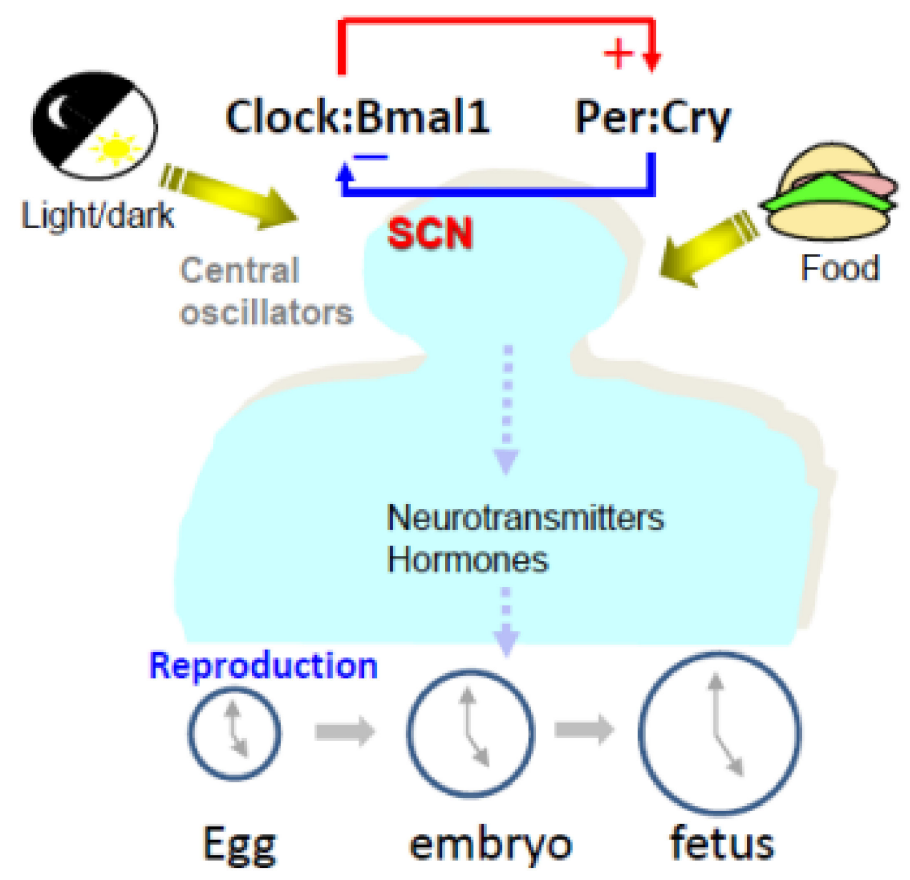

Figure 1. Light and Food intake are main input factors of circadian clock genes. In brain suprachiasmatic nucleus (SCN) as well as peripheral clock: Clock and Bmal1 heterodimerize to activate transcription of circadian target genes including the genes of Per $1 / 2 / 3$ and Cry1/2). Per and Cry interact and inhibit Bmal1 and Clock. Clock genes rhythm are present in a wide array of other tissues (including the liver, kidney, lung, heart, etc.) and these tissues have their own rhythm distinct from that of the SCN. SCN circadian clock can control behavior, feeding and reproduction through neurotransmitters and hormones to regulate reproduction.

The SCN, located in the hypothalamus, is linked to optic cues. In addition to being responsible for the establishment of endogenous rhythms in mammals, the SCN also influences the circadian timing in individual cells. The reproductive control of various species is connected to circadian rhythm via light and the length of days. This control is linked to a series of feedback loops in the SCN. Many aspects of reproductive biology are regulated by the circadian rhythm [29,30]. This includes the estrus cycle, levels of luteinizing hormone (LH), ovulation, production and maturation of sperm, fertilization, insemination, and embryo implantation $[23,31]$. This internal clock can subtly regulate or be an integral part of the process of reproduction. It has been found that the disruption of certain primary genes such as Clock and Bmal1 might have a detrimental effect on reproductive health [22,24]. Disruption of a single clock gene, in this case, specifically Bmal1, is enough to disrupt the reproductive cycle $[24,32,33]$. The extent to which other circadian clock genes affect the reproductive cycle is not fully known, however, there is evidence that disruption of these circadian clock genes will cause issues with most aspects of reproduction. As we know, reproduction is made of several processes, including, trigger ovulation, ovulation, fertilization, embryo development, uterine preparation, embryo implantation, placental support of fetus, zygote stage, embryonic stage, and the fetal stage [34-38]. During the past twenty years, circadian clock research has increased each year, and research pertaining to circadian clock regulation of reproduction has also increased (Figure 2). In this focused review, we will first 
introduce circadian clock proteins and then discuss their known, or hypothesized, roles in reproduction from recent research.
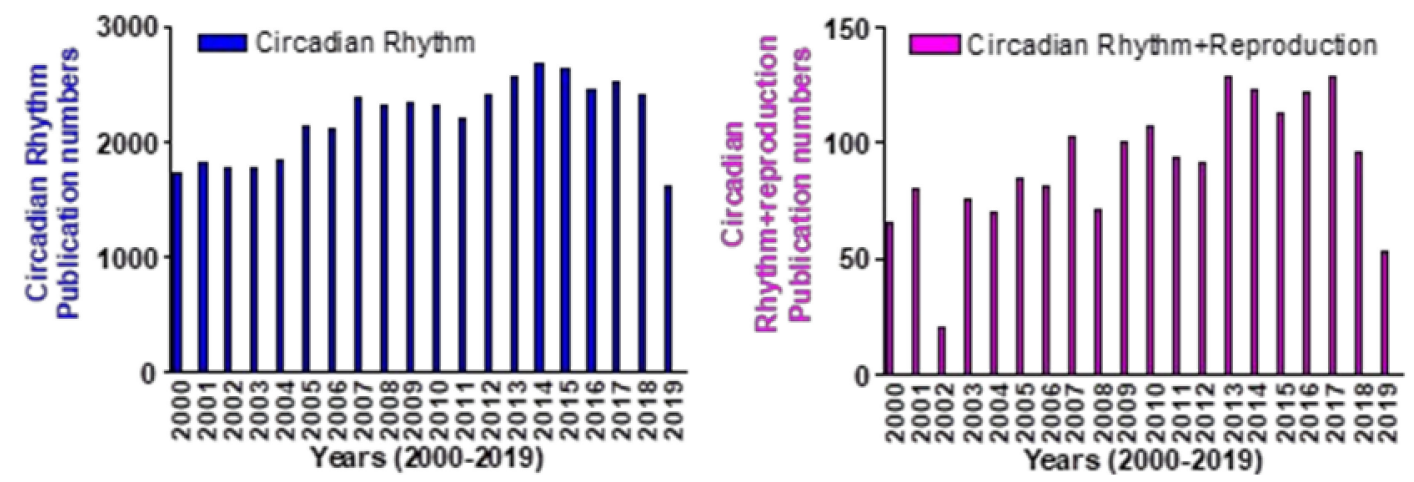

Figure 2. The number of references found for each year (From 2000 to 2019) of publication on the PubMed database using the keyword 'Circadian Rhythm' (left) or 'Circadian Rhythm + Reproduction' (right). In 2019, this number of Circadian Rhythm was 1621, the number of Circadian Rhythm reproduction was 53 .

\section{Light Cycle}

Studies have shown that there is an increased risk to pregnancy in female night-shift workers [39-42]. Exposure to artificial light at night has caused great concern as it leads to chronodisruption which harms the human biological clock, and causes possible negative effects in human pregnancy [39,43-48]. It has been proposed that disrupting the rhythmicity of the circadian system, as shown by an expected anomalous physiological response and gestational chronodisruption, can be translated from mother to offspring [49-51]. Studies investigating flight attendants demonstrated that miscarriages have an association with their sleep patterns during work, suggesting, disruptions of circadian rhythm may actuate a miscarriage [52-54]. To test the hypotheses surrounding circadian clock genes and reproduction, Goldstein et al. carried out experiments using mice [41]. They found that implantation of the embryo in the uterus is negatively impacted by circadian disruption, only impairing the uterus does not explain the negative pregnancy outcome during the maternal disruption of the circadian cycle. Goldstein et al. pointed out contributors to embryo quality, such as ovarian factors, and early embryo development may be the reproductive mechanisms most vulnerable to the detrimental effects of circadian disruption [41]. Impairment of the uterus by disturbing the mother's circadian cycle alone is not enough to disrupt the whole pregnancy. Therefore, the hypothesis is that there must also be upstream circadian disruptions [41]. Goldstein et al. postulated that both sets of these circadian genes must exhibit disruption in order for the pregnancy to fail [41]. If these circadian clock genes could be harnessed and redirected, they could be used as a potential cure for female infertility. In addition, repeated shifting of the light/day cycle can reduce the number of pregnancies and implantation sites in animal models [55]. This leads to a dramatic reduction in pregnancy success in mice [56]. This explains the relationship between circadian clock alterations and miscarriages and provides insight into the potential role it upholds within steroidogenesis in the human ovary.

\section{Embryonic Brain SCN}

Many of the body's processes and physiology function follow a natural circadian rhythm on a 24-hour day-night cycle. However, a female's fertility can be affected by the amount of light in modern society, shift work, or crossing time zones. Previous research has reported that light/dark cycle, genetic or environmental manipulations that altered the SCN timing signal and disrupted the circadian rhythms of older female mice affected reproductive cycling and function. Mammals are able to adapt to environmental changes, due to crucial biological functions of the SCN, particularly through circadian oscillators. The SCN exhibits rhythms of circadian clock gene expression and matures as the organism 
grows and develops. Circadian rhythms are synchronized by the SCN. This "master clock" relies on the functional role of the core clock proteins, Clock and Bmal1, which enables clock gene expression. As mentioned before, these circadian clock genes are all expressed in animal and human placenta, and their expression shows a potential circadian rhythm [26,57]. Several studies have shown the crucial role that the circadian clock and SCN play in female reproductive function $[21,22,58]$. For example, there have been SCN ablation studies that have revealed the role this central clock plays in regulating estrous cycles and ovulation in female rats $[29,59]$. The importance of the central clock in reproductive biology is also supported by the observation that deletion of the central clock, which occurs in SCN lesions or global deletion of Bmal1, corresponds to defects in estrous cycling and ovulation [60].

The hypothalamic SCN begins to regulate circadian rhythms during days 12-15 of gestation in mouse models [61]. Comparatively, the $\mathrm{SCN}$ is discernible as a discrete structure around the 18-30th week of pregnancy in humans. There is expression of Per 2 associated with circadian rhythm at embryonic day 16 (after fertilization), which is approximately equivalent to the end of the first trimester in humans [61]. Not only do these oscillations begin in the absence of vasoactive intestinal polypeptide (VIP), which is located in hypothalamic SCN (plays an important role in many biological functions) VIP-deficient mice exhibit severe disruptions in their ability to express a coherent rhythm in constant conditions. Per2 gene expression increased in intensity as time goes on, up to embryonic day 18 (although not to the adult levels of intensity) [61-63]. The Per2 circadian rhythm can even emerge in mice lacking a circadian clock such as Bmal1. Immunohistochemistry study determined expression of Per2 on day 18, and expression of Per1 on day 18 to day 19 in SCN [64]. These results suggest that the $\mathrm{SCN}$ 's ability to generate circadian oscillations at this age is a property specific to $\mathrm{SCN}$ development and differentiation [63]. The development of oscillations in vivo may be due to the tissue's autonomous programming, which could occur in isolation without signals from elsewhere in the embryo or from the mother. These data also show that the human SCN could be functional at the start of the second trimester (14 weeks of pregnancy) [65]. In order to determine when the fetal SCN clock develops in vivo, and whether a circadian rhythm results from a functional fetal clock, Houdek et al. demonstrated that at embryonic day (E19), rhythms in Per2 and Bmal1 expression were absent in the fetal SCN [66]. However, the expression of Rev-erb $\alpha$ (nuclear receptor subfamily 1 , group D, member 1 , Nr1d1), and other genes related to cellular activity were being driven rhythmically [66]. This suggests that the fetal clock does not operate at E19, but is functional at E21. Houdek et al. speculated that during the early stages in vivo, the developing fetal SCN clock could theoretically be entrained by oscillation of Nr1d which may be driven by the maternal, rather than the fetal circadian system [66]. During these experiments, it was found that the rat placentas expressed seven clock genes in a very zone-specific manner [66].

It is well known that the relationships between maternal and fetal circadian signals are complex and essential for a successful pregnancy. Mark et al. found that the potential effect of changes in these systems could extend into life, post-birth [34]. To evaluate such variables mentioned above in a rat model, Bmal1, Per2, Per3, Cry1, and Rev-Erb $\alpha$ mRNA gene expression showed circadian variations since postnatal day 3 (P3), and a reversal of their acrophases from P14 [34]. Additionally, the circadian rhythmicity of Clock was only demonstrated at P3, P16, and P21 [34]. This investigation reveals profound significance, as it is unique in addressing the ontogeny of clock genes, which confirms a progressive postnatal maturation of their circadian variation.

It is also important to understand each gene's role in reproduction. The next section will delve, in-depth, into each known circadian clock gene and their respective roles in reproduction.

\section{Circadian Gene Involved in Reproduction}

\subsection{PER1 1, 2, and 3}

Per1, Per2, and Per3 are a class of circadian clock genes, which act as transcriptional repressors, forming a core component of the circadian clock [12]. They are the three members of the period 
circadian protein homolog. Per1 is associated with cell proliferation and apoptosis and is involved in the initiation and progression of several cancers such as head-neck carcinoma, prostatic cancer, colorectal cancer, breast cancer, and endometrial cancer $[67,68]$. Per 2 is also associated with cellular proliferation and differentiation, playing an important role in the development of breast cancer, milk duct, and maintaining the polarity and morphology of the mammary epithelium [67,69-71]. Per3 is associated with poor morning gastric motility and may have a role in the time-keeping function of the gut [72]. Per3 in knockout (KO) mice has been shown to have a pivotal role in the embryonic development of the cerebral cortex [73].

Per mutant females need to have significantly more embryonal implantations in the uterus, in comparison to successfully delivered offspring. Regarding single Per1 and Per2 mutants, although fertile, they exhibit lower reproductive success than the control group, as occurs in aged wild-type (WT) mice. The role of Per3 in regulating metabolism and adiposity has also been described in animal studies [74,75]. Per1 and Per2 mutations cause advanced aging [76]. Aging single mutation female $\mathrm{Per}^{-/-}$and $\mathrm{Per} 2^{-/-}$mice, bear smaller litters than their WT counterparts. In addition, aging $\operatorname{Per} 1^{\mathrm{m} / \mathrm{m}} / \mathrm{Per} 2^{\mathrm{m} / \mathrm{m}}$ double mutation mice have a significantly reduced number of ovarian follicles, displaying a decrease in female fertility starting approximately at 20 weeks and have significantly fewer pups born from 32 weeks old and onwards [77]. The Per2 oscillation was increased in uteri endometrial stromal cells (UESCs) during implantation, and decreased during differentiation [78]. Cellular differentiation interferes with the circadian clockwork in differentiating cells. The circadian rhythms of Per 2 mRNA and its proteins can be seen in the uteri of pregnant rats during the implantation stage. Conversely, no circadian rhythm of the Per2 gene was observed in the uteri during differentiation [78]. The circadian rhythm of Per2 protein also showed a peak around early light periods and a dip around the onset of dark periods. However, the peak time of Per 2 protein level lagged nearly four hours behind its transcript. Recently, Zhang et al. have shown that Per1 also plays an important role in the regulation of progesterone in female production. Zhang et al. found Per1 knockout significantly down-regulated the expression of some progesterone receptor target genes and impaired human endometrial stromal cell decidualization via decreased FOXO1 (forkhead box O1) protein level [79]. Per1 and Per2 mutants exhibit lower reproductive success than controls, illustrating that proper oscillations of the core clock genes in reproductive tissues are crucial for orderly reproductive function. It remains to be determined whether Per3 plays a similar role in female reproduction.

\section{2. $C R Y 1 / C R Y 2$}

Cryptochrome-1, or Cry1, has major importance in the maintenance of circadian rhythmicity [80]. Cry1 is expressed in most organs, tissues, and cells, and encodes transcription factors that regulate the circadian clock in mammals [81]. Cry1 can heterodimerize with Per1, Per2, and Per3, to interact with the CLOCK: BMAL1 complex [80,81]. This serves to suppress the transcription-promoting activity of the complex for genes such as Per1, Per2, Per3, Cry2, and Wee1 (WEE1 G2 Checkpoint Kinase), in cells and different tissues with a ticking circadian clock [81]. Cry1 is known to regulate DNA damage repair, cell proliferation, and several biological processes $[32,82,83]$. Cry1 in female mice can stop meiosis of the oocytes and preimplantation of embryos, although that is not involved in circadian clock regulation [84]. Overall, the role of $\mathrm{Cry} 1$ in maintaining normal testis is important for development and function. By contrast, the $\mathrm{Cr} 2 \mathrm{2}$ gene is only shown to be involved in the reproduction of diapausing animals through the seasons. It remains largely unclear; however, what part Cry2 plays in reproduction and more work will have to be done to identity this exact role in the future.

\subsection{CLOCK}

Animal model studies, particularly in the setting of obesity, diabetes, atherosclerosis, or other metabolism syndrome conditions by Clock genes, have led to an increase in recognition that a multitude of rhythmic functions, such as reproductive tissues in mammals, are controlled by molecular 
clockwork $[5,13,15,48,85]$. Clock/Clock mutant mice have differences in pregnancies, with a higher rate of fetal absorption, serious dystocia, morphological abnormalities, and lower serum progesterone and estradiol levels $[24,86]$. When considering lactation, Clock mutant mice do not have a significant peak of either crouching behavior or prolactin, and the amount of secreted milk is lower than that of wild-type mice [24]. Circadian rhythms implement necessary functions for proper reproduction, sparking interest in evaluating whether there is a link between Clock genetic variants, and the impact of idiopathic recurrent spontaneous abortion (IRSA). Hodzic et al. explored groups consisting of participants with IRSA and investigated polymorphic sites in their Clock gene of 284 women [87]. Hodzic et al. used single-nucleotide polymorphism selection and genotyping to uncover a correlation between these variables in the genotype distribution of rs6850524 and rs11932595 in the Clock gene [87]. Furthermore, evidence demonstrates that the $G$ allele under the dominant model (GG+GC/CC) for rs6850524, as well as the $G$ allele under the dominant model (GG+GA/AA) for rs11932595, may serve as risk factors for recurrent spontaneous abortion (IRSA) [87]. Thus, the findings provide a reason to believe that the variability of the Clock gene may be connected with IRSA, prompting a need for further analysis.

Prior studies have indicated that the age-related decrease of melatonin is a consequence of functional changes linked to this system, which controls the sleep/wake cycle. Recently, Semenova et al. showed the circadian rhythms of melatonin secretion in menopausal women and its association with the Clock3111T/C polymorphism with regards to their ethnicity [88-90]. The study included 403 menopausal women from both Caucasian and Asian races, who were evaluated based on their diurnal sleepiness (using subthreshold insomnia and Epworth Sleepiness Scale), polymorphic genotyping, and a four-time per day collection of saliva samples for melatonin determination. Higher melatonin levels (1.40 times, $p<0.05)$ were detected in the early morning hours in the carriers of the TT-genotype compared to that in a group of carriers of the minor 3111C- allele [89]. Significant differences in the melatonin levels were found between the control and main group of Asian women carriers of the TT- genotype. This group had a lower hormone level during the day, evening, and night hours in women with insomnia $(1.68,1.80$, and 2.13 times, respectively) [89]. It was postulated that in the course of evolution, the allele played a protective role in the development of insomnia [90]. In addition, the Clock gene demonstrated a correlation with the male reproductive system and mutations of the gene have been shown to impact fertility. Ran-binding protein 9 (RANBP9) is a key factor in the development of the gonad [91]. With the intent of investigating spermatogenesis (and the extent to which the functional significance of Clock is involved), novel interacting proteins of Clock were determined using a yeast two-hybrid assay with cDNA fragments of the Clock PAS A domain and human testicular tissue. RANBP9 may prove to be a novel Clock-binding protein and show a direct interactive role between Clock and RANBP9 occurring both in vivo and in vitro [92]. Additionally, both Clock and RANBP9 may be a plausible component of splicing in spermatogenesis [92]. Essentially, Clock plays a role in the male reproductive system, and can be related to further studies that seek validation of the relationship between the role of circadian clock genes and spermatogenesis.

Neuronal PAS Domain Protein 2 (NPAS2), is an analog of CLOCK. Like the Clock gene, it has been associated with autism, seasonal variation of sleep length, social activity, mood, weight, appetite, and energy level $[93,94]$. Kovanen et al. showed, NPAS2 rs2305160 A allele-carriers had lower Global Seasonality Scores a sum score of six items, and carriers of the "A" allele, at NPAS2 rs6725296, had greater loadings on the metabolic factor (weight and appetite) of the global seasonality score from a health interview of an individual living in Finland [94]. This study suggested that NPAS2 gene variants are associated with reproduction. Understanding CLOCK and NPAS2 can lead to improved treatment strategies for reproduction.

\subsection{BMAL1}

Circadian clock genes contribute to reproductive processes in mammals. BMAL1 plays an essential role in female reproduction $[60,95]$. This includes several phenotypes such as the display of 
irregular estrous cycles, late onset of puberty, absence of proestrus LH surges, implantation failure, and progesterone-dependent implantation failure, as seen in global Bmal1 ${ }^{-/}$female mice $[60,95]$. Similarly, in global Bmal1 ${ }^{-/}$females, the deletion of Bmal1 in Steroidogenic Factor-1 (SF1)-Cre cells leads to implantation failure associated with low progesterone levels [96]. In SF1-Bmal1 ${ }^{-/-}$female mice, the failure of steroidogenic compartments of the pituitary (i.e., gonadotrophs), adrenal gland, or ovary can be seen. Liu et al. also found that in mice who received progesterone, pregnancy could be sustained, and the females had normal embryos, a normal number of implantation sites, and normal embryo development overall when compared to that in WT controls [96]. The circadian rhythm within the ovary is what determines embryo implantation success.

Bmal1 plays a role in the molecular clock of ovarian steroidogenic cells, the production of progesterone, and other aspects of female reproduction. Studies of this mechanism show that oxidative stress may impair oocyte quality, fertilization, and embryo development, and excess ROS can reduce oocyte quality, fertilization, and embryo development in Bmal1 ${ }^{-/}$female mice [97]. It is possible that in $\mathrm{Bmal1}^{-1-}$ females, the relatively higher fertilization rate and blastocyst number in vitro were due to the effect of a potent antioxidant contained in the G-series culture mediums that were used in the experiment, while in vivo the oocytes/early embryos were exposed to excess ROS in the oviduct. $\mathrm{Xu}$ et al. have tried to explore the effects of the disruption of female circadian rhythm on oocyte fertilization, pre-implantation embryo development, and blastocyst implantation [97]. During natural ovulation, the ovulated oocyte number of $\mathrm{Bmal1}^{+/+}$mice was higher than that of $\mathrm{Bmal1}^{-/-}$mice. They found significantly lower levels of fertilization and obtained blastocyst numbers in Bmal1 ${ }^{-/}$ mice compared with that in $\mathrm{Bmal1}^{+/+}$mice, after superovulation and being mated with wild-type males [97]. This study, which is consistent with other recent studies, showed that female Bmal1 ${ }^{-/}$mice were infertile [98]. Bmal1 ${ }^{-/-}$mice had lower levels of fertilization, Bmal1 ${ }^{-/-}$mice obtained blastocyst numbers compared with that of WT mice after superovulation and being mated with WT males [98]. Additionally, Mereness et al. reported that the deletion of Bmal1 had locus in ovarian granulosa cells (GCs) (Granulosa Cell Bmal1 KO; GCKO) or theca cells (TCs) (Theca Cell Bmal1 KO; TCKO) [99]. Mereness et al. also found phasic sensitivity to LH (luteinizing hormone) shown in WT littermate control (LC) and GCKO mice but not TCKO mice. TCKO mice were able to alter LH with impaired fertility [99]. TCKO mice were able to alter patterns of LH receptor mRNA abundance in the ovary but with less effect on the reproductive cycles, preovulatory LH secretion, ovarian morphology, and behavior. This indicates the process of follicle development and/or ovulation was at least partly affected due to disruption in circadian rhythm [99]. The theca cells is a pacemaker that modulates phasic sensitivity to LH that contributes to the timing and amplitude of ovulation, indicating an adverse environment existed before ovulation [99]. These data suggest that Bmal1 likely plays a more important role in reproduction than previously believed.

\subsection{Nocturnin}

Under the control of the circadian clock, Nocturnin has rhythmic expression in multiple mouse tissues $[11,100]$. Nocturnin is a hydrolase enzyme that is involved in metabolism and its expression is controlled by the rhythmic circadian clock. It is encoded by the Circadian Deadenylase NOC gene located on chromosome $4[100,101]$. Nocturnin not only plays a role in brown adipose tissue, metabolism amplitude, and lipid absorption, but also regulates mice reproduction [17,100-103]. Nocturnin has been shown to be a clock-controlled deadenylase in mouse oocytes and early embryos, although the circadian deadenylase Nocturnin expression has not been shown to be rhythmic in preimplantation embryos [101,104]. However, high level of Nocturnin expression has severely harmful effects on early embryonic development. Overexpression of Nocturnin has shown to significantly increase the expression of fatty acid-binding protein 4 and peroxisome proliferator-activated receptor- $\gamma 2$ [105]. The level of Nocturnin RNA expression has been shown to be the highest in mice oocytes, but it decreases after fertilization, with a slight increase after the 4-cell stage, up to the blastocyst stage $[104,105]$. NOCTURNIN protein expression levels have been shown to be constant during preimplantation in mice. 
Even after RNA levels decreased, there is evidence to suggest that there is some post transcriptional regulation of the gene's expression and Nocturnin is required for embryo maturation to take place.

\section{Neural Regulation}

In mammals, the SCN clock can work through various neural and endocrine inputs to peripheral tissues to align the sleep-wake cycle with behavioral and physiological oscillations, including body temperature, hormone levels, feeding, and metabolism [106,107]. Neurons have been shown to play an important role in reproduction [108,109]. The effects of the alteration of circadian rhythm via chemical sympathectomy (with 6-hydroxydopamine) or by cutting out a section of the vagus nerve have been shown in pregnant sheep [110]. The results showed a definite and modulating circadian rhythm of sleep cycling in fetuses. However, state-related cardiovascular rhythms were significantly modulated, indicating that the sympathetic nervous system, or vagal activity, is essential for generating cardiovascular diurnal rhythms in the late-gestation fetus [110]. Recently, Padilla et al. showed that Kiss $1^{A R H}$ neurons (hypothalamic arcuate nucleus Kiss1) affect circadian function [111]. Kisspeptin is an essential neuropeptide for reproduction, with high levels circulating throughout pregnancy [112,113]. Only female kiss receptor knockout mice become obese [114]. However, its full role remains unclear. Samples from healthy, full-term, placentas were taken at various time points during the day and tested. This demonstrated a circadian rhythm to placental kisspeptin levels [115]. De Pedro et al. speculated that kisspeptin plays a role in the timing of delivery, perhaps because it acts as a mediator between melatonin and oxytocin molecules, which are also known to play a role [116]. They found a clear increase in kisspeptin expression for morning deliveries over deliveries later at night [116]. This suggests that kisspeptin's function in reproduction is controlled by the circadian clock.

Agouti-related protein (AgRP) neurons also play an important role in reproduction [117]. Recently, Cedernaes et al. have reported that mice with AgRP-specific ablation of Bmal1 (ABKO) mice showed disrupted food intake patterns and increased body weight. ABKO mice have shown to increase hepatic gluconeogenesis and altering metabolism, suggesting that the molecular clock plays an important role in AgRP neurons [106]. How is circadian clock regulate neurons sensing this reproduction? It will be interesting to interrogate further whether such neurons sensing of circadian clock occurs in reproduction. Recent studies have shown that the evaluation of chronic AgRP neuron activation on female fertility has been tested using clozapine $\mathrm{N}$-oxide drinking water. This showed a five-day delay in infertility and an estrous cycle delay, together providing support that enhanced AgRP signaling weakens fertility [117]. The results provide a better understanding of the mechanical capabilities of AgRP neurons. It was revealed they attenuated fertility through inhibition of neuroendocrine reproductive-related neurons. Thus, concluding that several neurons participate in reproductive processes.

\section{Hormone Regulation}

\subsection{Melatonin}

SCN neurons synchronize peripheral tissue clocks through not only neuronal, but also hormonal pathways [2,24]. Circadian rhythm and melatonin affect fetal and maternal health and human reproductive success. The use of shift workers and electric lighting has disrupted this cycle and disturbed the optimal levels of melatonin in the blood as well $[118,119]$. The levels of melatonin in the follicular fluid during ovulation are higher than the levels found in human blood [120,121]. Several studies have reported the role of melatonin is seen not only in the labor and delivery mechanisms but also in ovulation and early pregnancy. Melatonin is produced at several sites in the ovary, and these, along with melatonin from the blood, help regulate the estrous cycle and protect against oxidative stress that contributes to multiple complications in human pregnancy [118,119,122].

When the mother maintains a normal, light/dark, and sleep/wake cycle, it helps to stabilize and maintain the fetus's circadian clock. Women must maintain an undisturbed light/dark cycle. This helps maintain the circadian clock and preserve the melatonin cycle. Ongoing or extreme disturbances of 
this rhythm can lead to an adverse effect on the fetus/newborn [122]. Owing to this, it is suggested that the mother, especially during the third trimester, should avoid such disturbances, including shift work and bright light at night [123]. Due to melatonin levels being higher at night and its link with oxytocin, higher melatonin levels may account for higher chances of childbirth at night.

Whenever this light/dark cycle is disturbed, either because of nighttime disturbance by artificial light or by shift work, it throws off the mother's circadian clock and suppresses the melatonin cycle, thereby affecting the developing fetus. Melatonin has many effects on the body from inducing a state of sleep to regulating circadian rhythms. Since the embryo cannot produce its own melatonin until after birth, it is reliant on melatonin from the mother $[118,122,123]$. This maternal influence seems to follow the embryo from oocyte through normal development, until birth. The levels of melatonin increase throughout gestation, first increasing at night after 24 weeks of gestation and then increasing significantly after 32 weeks [118,122]. The addition of melatonin has a positive outcome on high-risk pregnancies. The effects of melatonin may not just be limited to the regulation of circadian rhythms, but further investigation is required. Maternal melatonin is low during the day and increases at night. Additionally, the suppression of melatonin via continuous light exposure had several detrimental effects on fetal growth. It limited intrauterine growth, affected the levels of expression of several clock genes, and lowered the levels of corticosterone, and modified its usage [118,122]. However, these effects were reversed when the mother received a daily injection of melatonin. This is also backed by previous studies that show the negative effects of shift work, jet lag, and daylight savings time on pregnancy and in vitro fertilization (IVF) outcomes [124,125]. This is particularly useful in IVF since a primary cause for infertility is poor oocyte quality. Since it is well established that melatonin helps combat poor oocyte quality and mutations during maturation, melatonin treatment during human pregnancy may help combat some of these stresses and could be used as a treatment for infertility in some cases [125]. Melatonin is already used in some cases during assisted reproductive technologies and IVF. Treating this disruption in pregnant mothers with melatonin can reset the fetal clock via the adrenal gland [125]. Fetuses, whose mothers were exposed to constant light, had lower weight, and the constant light exposure had a negative effect on the fetal circadian clock in the adrenal gland. Maternal exposure to constant light has a negative effect on the cellular response to the adrenocorticotropic release of corticosterone and relative mRNA expression [126]. Fetal growth can be affected in addition to fetal adrenal function due to maternal exposure to constant light [127]. However, these effects could be reversed when the mother receives a daily dose of melatonin during the subjective night.

Recently, Zhang et al. showed the relationship between long light exposure and negative effects on embryo implantation and pregnancy success (mimicking light pollution). Female mice who underwent spontaneous estrous were placed with fertile males and then checked for plugs the next morning [128]. These plugged females were then used for the experiment. The administration of melatonin rescued the negative effect of long light exposure. Melatonin probably increases $17 \beta$-estradiol levels during pregnancy and upregulates tumor protein p53 expression by activating melatonin receptors type 1 or 2 in the uterus [128]. This activation likely changes the uterine microenvironment for the better and increases the chance of a positive pregnancy outcome via increased successful embryo implantation. In short, melatonin is important in the development of the fetal circadian clock, helps with the development of the neurological and endocrine systems, and helps protect the embryo/fetus from metabolic stresses that can cause damage to the growing pregnancy.

\subsection{Estrogen}

Estrogen, as an ovarian hormone, is associated with suppressed food intake and produces important anti-obesity and antidiabetic effects in female animals $[129,130]$. It has shown that circadian clock gene Per2 has a link with the estrogen receptor [131]. Recently, Nakamura et al., showed that estrogen directly affects the timing of the molecular clock in the uterus via an estrogen receptor-mediated response [132]. In addition, estrogen has been shown to differentially regulate the expression of Per1 and Per 2 genes between central and peripheral clocks and between reproductive and nonreproductive 
tissues in female animals [132]. Estrogen has been known to account for this sexual dimorphism and is abolished in postmenopausal women $[130,133,134]$. In addition to its limited role, this hormone may also play another, yet unappreciated, role in the regulation of the circadian clock and reproduction.

\subsection{Cortisol}

Cortisol is a steroid hormone, our body's main stress hormone. It is one hormone in the glucocorticoid class of hormones, to aid in the metabolism of fat, protein, and carbohydrates [124]. Cortisol also plays an important role in reproduction. In the rodent and human fetus, the diurnal rhythm of cortisol is observed to have the opposite pattern to the maternal rhythm. However, the adrenal circadian rhythm is not synchronized with the clock time after birth [124]. A few months later, a 24-h rhythm can be seen. In a newborn infant, the peak of cortisol level is observed in the late afternoon, in correspondence with the birth time [135]. Iwata et al. suggested that the adrenal circadian clock might play an important role in controlling reproduction [136]. To further determine the role of cortisol in reproduction, cortisol samples were collected at home from the saliva, both at night and first thing in the morning for analysis. There were no group differences in evening or morning cortisol levels. However, children with higher levels of prenatal cocaine exposure showed a blunted increase in cortisol levels between evening and morning measurements, especially compared to non-exposed children [136]. These studies suggest that extensive maternal use of cocaine during pregnancy may constitute constant stress, which results in increased maternal and fetal cortisol secretion and prolonged exposure to elevated cortisol levels. Thus, further research regarding these factors is warranted to know more about the involvement of circadian regulation performed by cortisol in the reproductive process.

\section{High Fat Diet \& Time-Restricted Feeding Regulation}

There is strong evidence that high caloric intake has negative impacts on principal body functions, such as endocrine effects, altered liver metabolism, and cholesterol imbalance [137-139]. Developmental programming, an action associated with nutrition during pregnancy and early life, imposes continual effects on the health of offspring, as shown through the reproductive repercussions of high-fat diets (HFD) $[140,141]$. It has been demonstrated that high fat and sugar intake induces alterations in circadian clock function, which seems to be a factor in female reproductive timing, since such changes may harm synchronization between circadian rhythmicity and central or peripheral components. Recently, several studies have shown that high caloric intake leads to premature aging, altered sleep, and disruption in circadian rhythmicity [141-144]. Highlighting their significance, high-fat diet intake affects the ovarian circadian clock [145]. Circadian core gene expression within ovarian cells revealed changes as a result of maternal and post-weaning high-fat diets [142,145]. Time-restricted feeding (TRF) has been known to prevent body weight gain associated with HFD feeding ad libitum in all genotypes without reducing food intake or increasing activity [146-148]. We have shown that TRF modifies clock genes and abetalipoproteinemia genes microsomal triglyceride transfer protein (MTTP) expression pattern. The Mttp KO mice died early during embryonic development, with reduced lipoprotein secretion in heterozygotes and embryonic lethality in homozygotes $[19,149,150]$.

Several studies have suggested that erratic eating patterns increase the risk of disease. A defined daily feeding-fasting rhythm, as in TRF, is positively related to reducing risk of breast cancer and other chronic diseases [151-153]. Prior research has shown that TRF can negatively influence LH pulsatility in prepubertal cycling gilts during ovarian development. Furthermore, TRF has been shown to decrease gonadotropin concentration in humans $[154,155]$. An early study showed that TRF modulates neuronal orexigenic neuropeptide Y (NPY) gene expression during the phase with low leptin levels and the action of leptin on LH secretion via variation in the availability of glucose. TRF has been known to increase hypothalamic NPY gene expression; this might result from the coordinated action of several factors, such as reducing serum leptin and insulin concentrations. Similar TRF effects have been observed in several studies. Increased NPY levels might inhibit GnRH release during some periods of the feeding cycle [156-159]. In a recent study, ten-hour TRF was shown to reduce weight, blood pressure, 
and atherogenic lipids in patients with metabolic syndrome. Like light, TRF coordinates internal biological rhythms with the environment. Gestational circadian rhythm of newborn pups is affected by external cues or via the mother's own circadian clock [160]. Novakova et al. showed that rat's pups in a regular light-dark cycle with food restriction did not exhibit any noticeable changes in their circadian clock [161]. However, those animals under constant light with food restriction showed a restoration of circadian rhythm, indicating that when regular external clues are lacking, regular feeding by the animal's mother may help pups maintain an internal clock [160]. Nevertheless, these studies may help understand the important translation of TRF in reproductive health to provide new therapeutic opportunities to treat shift-work induced reproductive failure and improve the health and well-being of infants.

\section{Future Directions and Perspectives}

Although our and other reviews are starting to piece together the early events and identify proteins involved in animal reproduction, very little is known about circadian rhythm disruption in humans. It is well known that animal models, although useful, do not completely mirror the human reproductive system, especially with respect to hormonal fluctuations as well as circadian rhythm disruption. Therefore, the need for more studies on the effect of the disruption of circadian rhythms in human fertility is required. It should be noted, however, that external effects cannot be ruled out, such as the stress of vaginal delivery, including the increase in stress hormones known to affect gene expression. Only two of the genes studied-Clock and Bmal1, showed any circadian variation [26].

The developing fetus receives essential nutrients based on the mother's metabolic changes during two specific maternal metabolic phases, the anabolic and catabolic phases. This process of metabolic homeostasis is increasingly recognized to share a link with circadian variation. This is stimulated by the work of clock genes, and also shares importance with maternal carbohydrate and fat metabolism, since glucose and lipids are the fetus's primary energy source. For example, in mice, a mother's adaptation to pregnancy includes shifts in clock genes within the liver that results in a reduction of the circadian clock that regulates glucose. This variation in circadian regulation of glucose metabolism, midway through gestation, ensures a sustainable supply of glucose to meet the demands of fetal growth. Investigating the relationship between the internal circadian clock and metabolic abnormalities in pregnancies, serum triglycerides in mice increase in later pregnancy and fluctuate throughout the light/dark cycle. In humans, postprandial serum triglyceride levels are high [98]. These data suggest that there is an increase in serum triglyceride levels in the third trimester after a high-calorie lunch compared to levels in non-pregnant women.

Recently, we have shown that plasma triglyceride showed diurnal rhythm in WT mice, and ApoAIV (Apolipoprotein A IV) and MTTP plays an important role in adult mice hepatocytes triglyceride and Very Low-Density Lipoproteins (VLDL) production. TRF in day time, shift the peak of hepatocytes ApoAIV and MTTP gene expression in mice with 12 light/12 dark cycle [19,162-164]. In addition, Clock proteins play an important role in the diurnal rhythm of plasma triglycerides [19,149]. It will be interesting to interrogate further whether such lipid metabolism genes occur in localized regions from the egg, to the embryo, to the fetus, undergoing triglyceride production and through a similar mechanism as suggested for adult circadian clock regulation. However, variations in the expression of circadian clock genes in different tissues and TRF are the components of maternal metabolic adaptation in pregnancy. Such changes promote variation in circadian expression of metabolic genes involved in glucose and lipid homeostasis. In addition, the nature of the relationship between a mother's metabolism of carbohydrates, fat, and protein, and energy consumption by the developing fetus remains unclear. Identification of other proteins involved in the reproductive process may provide novel targets for the treatment of circadian clock (sleep) disorder-associated diseases such as reproductive failure. 
Author Contributions: Conceptualization and writing first draft, X.P.; writing original draft preparation, X.P.; M.J.T.; and E.C.; editing, X.P.; M.J.T.; E.C.; N.H.; and S.M.; reading and commenting, X.P.; M.J.T.; E.C.; N.H. and S.M. All authors have read and agree to the published version of the manuscript.

Funding: This work was supported in part by NIH National Heart, Lung, and Blood Institute Grant R56 HL137912-01 and American Heart Association Grant-In-Aid 16GRNT30960027 to X. Pan.

Conflicts of Interest: The authors declare no conflict of interest.

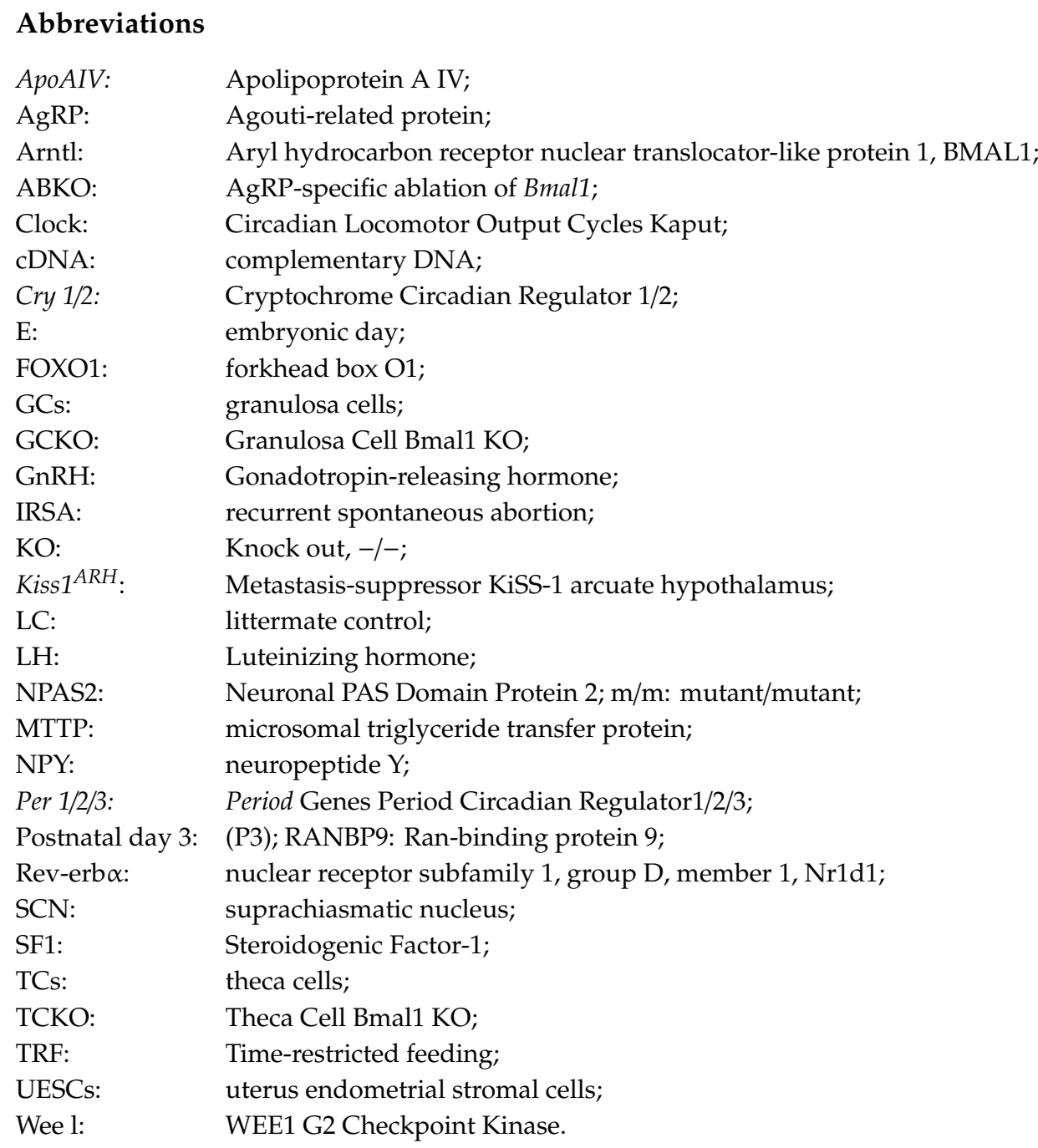

\section{References}

1. Takahashi, J.S. Molecular components of the circadian clock in mammals. Diabetes Obes. Metab. 2015, $17,6-11$.

2. Mohawk, J.A.; Green, C.B.; Takahashi, J.S. Central and peripheral circadian clocks in mammals. Annu. Rev. Neurosci. 2012, 35, 445-462.

3. Hussain, M.M.; Pan, X. Circadian Regulation of Macronutrient Absorption. J. Biol Rhythms 2015, 30, 459-469.

4. Darlington, T.K.; Wager-Smith, K.; Ceriani, M.F.; Staknis, D.; Gekakis, N.; Steeves, T.D.; Gekakis, N.; Steeves, T.D.; Weitz, C.J.; Takahashi, J.S. Closing the circadian loop: CLOCK-induced transcription of its own inhibitors per and tim. Science 1998, 280, 1599-1603.

5. Marcheva, B.; Ramsey, K.M.; Peek, C.B.; Affinati, A.; Maury, E.; Bass, J. Circadian clocks and metabolism. Handb. Exp. Pharmacol. 2013, 1, 127-155.

6. Kraft, M.; Martin, R.J. Chronobiology and chronotherapy in medicine. Dis Mon. 1995, 41, 506-575.

7. Loudon, A.S. Circadian biology: A 2.5 billion year old clock. Curr. Biol. 2012, 22, R570-R571.

8. Zhang, R.; Lahens, N.F.; Balance, H.I.; Hughes, M.E.; Hogenesch, J.B. A circadian gene expression atlas in mammals: Implications for biology and medicine. Proc. Natl. Acad. Sci. USA 2014, 111, 16219-16224. 
9. Froy, O. Metabolism and circadian rhythms-implications for obesity. Endocr. Rev. 2010, 31, 1-24.

10. Bass, J. Circadian topology of metabolism. Nature 2012, 491, 348-356.

11. Green, C.B.; Takahashi, J.S.; Bass, J. The meter of metabolism. Cell 2008, 134, 728-742.

12. Dibner, C.; Schibler, U. Body clocks: Time for the Nobel Prize. Acta Physiol. (Oxf.) 2018, 1, 222.

13. Hussain, M.M.; Pan, X. Circadian regulators of intestinal lipid absorption. J. Lipid Res. 2015, 56, 761-770.

14. Pan, X.; Bradfield, C.A.; Hussain, M.M. Global and hepatocyte-specific ablation of Bmal1 induces hyperlipidaemia and enhances atherosclerosis. Nat. Commun. 2016, 7, 13011.

15. Pan, X.; Jiang, X.C.; Hussain, M.M. Impaired cholesterol metabolism and enhanced atherosclerosis in clock mutant mice. Circulation. 2013, 128, 1758-1769.

16. Sato, F.; Kohsaka, A.; Bhawal, U.K.; Muragaki, Y. Potential Roles of Dec and Bmal1 Genes in Interconnecting Circadian Clock and Energy Metabolism. Int. J. Mol. Sci. 2018, 1, 19.

17. Douris, N.; Kojima, S.; Pan, X.; Lerch-Gaggl, A.F.; Duong, S.Q.; Hussain, M.M.; Green, C.B. Nocturnin regulates circadian trafficking of dietary lipid in intestinal enterocytes. Curr. Biol. 2011, 21, 1347-1355.

18. Hussain, M.M.; Pan, X. Clock genes, intestinal transport and plasma lipid homeostasis. Trends Endocrinol. Metab. 2009, 20, 177-185.

19. Pan, X.; Hussain, M.M. Clock is important for food and circadian regulation of macronutrient absorption in mice. J. Lipid Res. 2009, 50, 1800-1813.

20. Sussman, W.; Stevenson, M.; Mowdawalla, C.; Mota, S.; Ragolia, L.; Pan, X. BMAL1 controls glucose uptake through paired-homeodomain transcription factor 4 in differentiated Caco-2 cells. Am. J. Physiol. Cell Physiol. 2019, 317, C492-C501.

21. Brown, S.A. Circadian Metabolism: From Mechanisms to Metabolomics and Medicine. Trends Endocrinol. Metab. 2016, 27, 415-426.

22. Sellix, M.T. Clocks underneath: The role of peripheral clocks in the timing of female reproductive physiology. Front. Endocrinol. (Lausanne) 2013, 4, 91.

23. Gray, G.D.; Soderstein, P.; Tallentire, D.; Davidson, J.M. Effects of lesions in various structures of the suprachiasmatic-preoptic region on LH regulation and sexual behavior in female rats. Neuroendocrinology 1978, 25, 174-191.

24. Miller, B.H.; Takahashi, J.S. Central circadian control of female reproductive function. Front. Endocrinol. (Lausanne) 2013, 4, 195.

25. Downs, J.L.; Wise, P.M. The role of the brain in female reproductive aging. Mol. Cell Endocrinol. 2009, 299, 32-38.

26. Perez, S.; Murias, L.; Fernandez-Plaza, C.; Diaz, I.; Gonzalez, C.; Otero, J.; Elena, D. Evidence for clock genes circadian rhythms in human full-term placenta. Syst. Biol. Reprod. Med. 2015, 61, 360-366.

27. Brown, A.J.; Pendergast, J.S.; Yamazaki, S. Peripheral Circadian Oscillators. Yale J. Biol. Med. 2019, 92, 327-335.

28. Xu, Y.; Pi, W.; Rudic, R.D. Old and New Roles and Evolving Complexities of Cardiovascular Clocks. Yale J. Biol. Med. 2019, 92, 283-290.

29. Brown-Grant, K.; Raisman, G. Abnormalities in reproductive function associated with the destruction of the suprachiasmatic nuclei in female rats. Proc. R. Soc. Lond. B Biol. Sci. 1977, 198, 279-296.

30. Brown-Grant, K.; Murray, M.A.; Raisman, G.; Sood, M.C. Reproductive function in male and female rats following extra- and intra-hypothalamic lesions. Proc. R. Soc. Lond. B Biol. Sci. 1977, 198, 267-278.

31. Christian, C.A.; Mobley, J.L.; Moenter, S.M. Diurnal and estradiol-dependent changes in gonadotropin-releasing hormone neuron firing activity. Proc. Natl. Acad. Sci. USA 2005, 102, 15682-15687.

32. Honma, S.; Yasuda, T.; Yasui, A.; van der Horst, G.T.; Honma, K. Circadian behavioral rhythms in Cry1/Cry2 double-deficient mice induced by methamphetamine. J. Biol. Rhythm. 2008, 23, 91-94.

33. Chu, A.; Zhu, L.; Blum, I.D.; Mai, O.; Leliavski, A.; Fahrenkrug, J.; Oster, H.; Boehm, U.; Storch, K.F. Global but not gonadotrope-specific disruption of Bmal1 abolishes the luteinizing hormone surge without affecting ovulation. Endocrinology 2013, 154, 2924-2935.

34. Mark, P.J.; Crew, R.C.; Wharfe, M.D.; Waddell, B.J. Rhythmic Three-Part Harmony; The Complex Interaction of Maternal, Placental and Fetal Circadian Systems. J. Biol. Rhythm. 2017, 32, 534-549.

35. Kamity, R.; Hanna, N. Chlorhexidine baths in preterm infants-Are we there yet? J. Perinatol 2019, 39, 1014-1015.

36. Reppert, S.M. Pre-natal development of a hypothalamic biological clock. Prog. Brain Res. 1992, 93, $119-131$.

37. Boden, M.J.; Kennaway, D.J. Circadian rhythms and reproduction. Reproduction 2006, 132, 379-392. 
38. Caba, M.; Gonzalez-Mariscal, G.; Meza, E. Circadian Rhythms and Clock Genes in Reproduction, Insights from Behavior and the Female Rabbit's Brain. Front. Endocrinol. (Lausanne) 2018, 9, 106.

39. Lawson, C.C.; Whelan, E.A.; Lividoti Hibert, E.N.; Spiegelman, D.; Schernhammer, E.S.; Rich-Edwards, J.W. Rotating shift work and menstrual cycle characteristics. Epidemiology 2011, 22, 305-312.

40. Navara, K.J.; Nelson, R.J. The dark side of light at night; Physiological, epidemiological, and ecological consequences. J. Pineal Res. 2007, 43, 215-224.

41. Goldstein, C.A.; O'Brien, L.M.; Bergin, I.L.; Saunders, T.L. The effect of repeated light-dark shifts on uterine receptivity and early gestation in mice undergoing embryo transfer. Syst. Biol. Reprod. Med. 2018, 64, $103-111$.

42. Chen, J.D.; Lin, Y.C.; Hsiao, S.T. Obesity and high blood pressure of 12-hour night shift female clean-room workers. Chronobiol. Int. 2010, 27, 334-344.

43. Zhu, J.L.; Hjollund, N.H.; Andersen, A.M.; Olsen, J. Shift work, job stress, and late fetal loss: The National Birth Cohort in Denmark. J. Occup Environ. Med. 2004, 46, 1144-1149.

44. Whelan, E.A.; Lawson, C.C.; Grajewski, B.; Hibert, E.N.; Spiegelman, D.; Rich-Edwards, J.W. Work schedule during pregnancy and spontaneous abortion. Epidemiology 2007, 18, 350-355.

45. Stocker, L.J.; Macklon, N.S.; Cheong, Y.C.; Bewley, S.J. Influence of shift work on early reproductive outcomes: A systematic review and meta-analysis. Obstet Gynecol. 2014, 124, 99-110.

46. Bisanti, L.; Olsen, J.; Basso, O.; Thonneau, P.; Karmaus, W. Shift work and subfecundity: A European multicenter study. European Study Group on Infertility and Subfecundity. J. Occup Environ. Med. 1996, 38, 352-358.

47. Sallmen, M.; Anttila, A.; Lindbohm, M.L.; Kyyronen, P.; Taskinen, H.; Hemminki, K. Time to pregnancy among women occupationally exposed to lead. J. Occup. Environ. Med. 1995, 37, 931-934.

48. Bass, J.; Lazar, M.A. Circadian time signatures of fitness and disease. Science 2016, 354, 994-999.

49. Amaral, F.G.; Castrucci, A.M.; Cipolla-Neto, J.; Poletini, M.O.; Mendez, N.; Richter, H.G.; Sellix, M.T. Environmental control of biological rhythms, Effects on development, fertility and metabolism. J. Neuroendocrinol. 2014, 26, 603-612.

50. Mendez, N.; Halabi, D.; Spichiger, C.; Salazar, E.R.; Vergara, K.; Alonso-Vasquez, P.; Carmona, P.; Sarmiento, J.M.; Richter, H.G.; Seron-Ferre, M.; Torres-Farfan, C. Gestational Chronodisruption Impairs Circadian Physiology in Rat Male Offspring, Increasing the Risk of Chronic Disease. Endocrinology 2016, $157,4654-4668$.

51. Mendez, N.; Abarzua-Catalan, L.; Vilches, N.; Galdames, H.A.; Spichiger, C.; Richter, H.G.; Valenzuela, G.J.; Seron-Ferre, M.; Torres-Farfan, C. Timed maternal melatonin treatment reverses circadian disruption of the fetal adrenal clock imposed by exposure to constant light. PLoS ONE 2012, 7, e42713.

52. Grajewski, B.; Whelan, E.A.; Lawson, C.C.; Hein, M.J.; Waters, M.A.; Anderson, J.L.; MacDonald, L.A.; Mertens, C.J.; Tseng, C.Y.; Cassinelli, R.T. Miscarriage among flight attendants. Epidemiology 2015, 26, 192-203.

53. Grajewski, B.; Whelan, E.A.; Nguyen, M.M.; Kwan, L.; Cole, R.J. Sleep Disturbance in Female Flight Attendants and Teachers. Aerosp Med. Hum. Perform. 2016, 87, 638-645.

54. Radowicka, M.; Pietrzak, B.; Wielgos, M. Assessment of the occurrence of menstrual disorders in female flight attendants-Preliminary report and literature review. Neuro. Endocrinol. Lett. 2013, 34, 809-813.

55. Endo, A.; Watanabe, T. Effects of non-24-hour days on reproductive efficacy and embryonic development in mice. Gamete Res. 1989, 22, 435-441.

56. Summa, K.C.; Vitaterna, M.H.; Turek, F.W. Environmental perturbation of the circadian clock disrupts pregnancy in the mouse. PLoS ONE 2012, 7, e37668.

57. Phillippe, M.; Sawyer, M.R.; Edelson, P.K. The telomere gestational clock: Increasing short telomeres at term in the mouse. Am. J. Obstet. Gynecol. 2019, 220, 496.

58. Varcoe, T.J.; Voultsios, A.; Gatford, K.L.; Kennaway, D.J. The impact of prenatal circadian rhythm disruption on pregnancy outcomes and long-term metabolic health of mice progeny. Chronobiol. Int. 2016, 33, 1171-1181.

59. Wiegand, S.J.; Terasawa, E.; Bridson, W.E.; Goy, R.W. Effects of discrete lesions of preoptic and suprachiasmatic structures in the female rat. Alterations in the feedback regulation of gonadotropin secretion. Neuroendocrinology 1980, 31, 147-157.

60. Boden, M.J.; Varcoe, T.J.; Voultsios, A.; Kennaway, D.J. Reproductive biology of female Bmal1 null mice. Reproduction 2010, 139, 1077-1090.

61. Wreschnig, D.; Dolatshad, H.; Davis, F.C. Embryonic development of circadian oscillations in the mouse hypothalamus. J. Biol. Rhythm. 2014, 29, 299-310. 
62. Loh, D.H.; Dragich, J.M.; Kudo, T.; Schroeder, A.M.; Nakamura, T.J.; Waschek, J.A.; Block, G.D.; Colwell, C.S. Effects of vasoactive intestinal peptide genotype on circadian gene expression in the suprachiasmatic nucleus and peripheral organs. J. Biol. Rhythm. 2011, 26, 200-209.

63. Maywood, E.S.; Chesham, J.E.; O’Brien, J.A.; Hastings, M.H. A diversity of paracrine signals sustains molecular circadian cycling in suprachiasmatic nucleus circuits. Proc. Natl. Acad. Sci. USA 2011, 108, 14306-14311.

64. Shimomura, H.; Moriya, T.; Sudo, M.; Wakamatsu, H.; Akiyama, M.; Miyake, Y.; Shibata, S. Differential daily expression of Per1 and Per2 mRNA in the suprachiasmatic nucleus of fetal and early postnatal mice. Eur. J. Neurosci. 2001, 13, 687-693.

65. Rivkees, S.A. The Development of Circadian Rhythms, from Animals to Humans. Sleep Med. Clin. 2007, 2, 331-341.

66. Houdek, P.; Sumova, A. In vivo initiation of clock gene expression rhythmicity in fetal rat suprachiasmatic nuclei. PLOS ONE 2014, 9, e107360.

67. Zheng, B.; Albrecht, U.; Kaasik, K.; Sage, M.; Lu, W.; Vaishnav, S.; Li, Q.; Sun, Z.S.; Eichele, G.; Bradley, A.; Lee, C.C. Nonredundant roles of the mPer1 and mPer2 genes in the mammalian circadian clock. Cell 2001, 105, 683-694.

68. Sato, F.; Nagata, C.; Liu, Y.; Suzuki, T.; Kondo, J.; Morohashi, S.; Imaizumi, T.; Kato, Y.; Kijima, H. PERIOD1 is an anti-apoptotic factor in human pancreatic and hepatic cancer cells. J. Biochem. 2009, 146, 833-838.

69. Zheng, B.; Larkin, D.W.; Albrecht, U.; Sun, Z.S.; Sage, M.; Eichele, G.; Lee, C.C.; Bradley, A. The mPer2 gene encodes a functional component of the mammalian circadian clock. Nature 1999, 400, 169-173.

70. Xu, Y.; Toh, K.L.; Jones, C.R.; Shin, J.Y.; Fu, Y.H.; Ptacek, L.J. Modeling of a human circadian mutation yields insights into clock regulation by PER2. Cell 2007, 128, 59-70.

71. McQueen, C.M.; Schmitt, E.E.; Sarkar, T.R.; Elswood, J.; Metz, R.P.; Earnest, D.; Rijnkets, M.; Porter, W.W. PER2 regulation of mammary gland development. Development 2018, 145. [CrossRef]

72. Hoogerwerf, W.A. Role of clock genes in gastrointestinal motility. Am. J. Physiol. Gastrointest. Liver Physiol. 2010, 299, G549-G555.

73. Noda, M.; Iwamoto, I.; Tabata, H.; Yamagata, T.; Ito, H.; Nagata, K.I. Role of Per3, a circadian clock gene, in embryonic development of mouse cerebral cortex. Sci. Rep. 2019, 9, 5874.

74. Aggarwal, A.; Costa, M.J.; Rivero-Gutierrez, B.; Ji, L.; Morgan, S.L.; Feldman, B.J. The Circadian Clock Regulates Adipogenesis by a Per3 Crosstalk Pathway to Klf15. Cell Rep. 2017, 21, 2367-2375.

75. Shearman, L.P.; Sriram, S.; Weaver, D.R.; Maywood, E.S.; Chaves, I.; Zheng, B.; Kume, K.; Lee, C.C.; van der Horst, G.T.; Hasting, M.H.; et al. Interacting molecular loops in the mammalian circadian clock. Science 2000, $288,1013-1019$.

76. Sellix, M.T. Circadian clock function in the mammalian ovary. J. Biol. Rhythm. 2015, 30, 7-19.

77. Zheng, Y.; Liu, C.; Li, Y.; Jiang, H.; Yang, P.; Tang, J.; Xu, Y.; Wang, H.; He, Y. Loss-of-function mutations with circadian rhythm regulator Per1/Per2 lead to premature ovarian insufficiencydagger. Biol. Reprod. 2019, 100, 1066-1072.

78. Tasaki, H.; Zhao, L.; Isayama, K.; Chen, H.; Nobuhiko, Y.; Yasufumi, S.; Hashimoto, S.; Hattori, M.A. Profiling of circadian genes expressed in the uterus endometrial stromal cells of pregnant rats as revealed by DNA microarray coupled with RNA interference. Front. Endocrinol. (Lausanne) 2013, 4, 82.

79. Zhang, Y.; Meng, N.; Bao, H.; Jiang, Y.; Yang, N.; Wu, K.; Wu, J.; Wang, H.; Kong, S.; Zhang, Y. Circadian gene PER1 senses progesterone signal during human endometrial decidualization. J. Endocrinol. $2019,243$. [CrossRef]

80. Ye, R.; Selby, C.P.; Chiou, Y.Y.; Ozkan-Dagliyan, I.; Gaddameedhi, S.; Sancar, A. Dual modes of CLOCK, BMAL1 inhibition mediated by Cryptochrome and Period proteins in the mammalian circadian clock. Genes Dev. 2014, 28, 1989-1998.

81. Sancar, A.; Lindsey-Boltz, L.A.; Gaddameedhi, S.; Selby, C.P.; Ye, R.; Chiou, Y.Y.; Kemp, M.G.; Hu, J.; Ozturk, N. Circadian clock, cancer, and chemotherapy. Biochemistry 2015, 54, 110-123.

82. Kang, T.H.; Leem, S.H. Modulation of ATR-mediated DNA damage checkpoint response by cryptochrome 1. Nucleic Acids Res. 2014, 42, 4427-4434.

83. Ono, D.; Honma, S.; Honma, K. Postnatal constant light compensates Cryptochrome1 and 2 double deficiency for disruption of circadian behavioral rhythms in mice under constant dark. PLoS ONE 2013, 8, e80615. 
84. Amano, T.; Matsushita, A.; Hatanaka, Y.; Watanabe, T.; Oishi, K.; Ishida, N.; Anzai, M.; Mitani, T.; Kato, H.; Kishigami, S.; et al. Expression and functional analyses of circadian genes in mouse oocytes and preimplantation embryos: Cry1 is involved in the meiotic process independently of circadian clock regulation. Biol. Reprod. 2009, 80, 473-483.

85. Turek, F.W.; Joshu, C.; Kohsaka, A.; Lin, E.; Ivanova, G.; McDearmon, E. Obesity and metabolic syndrome in circadian Clock mutant mice. Science 2005, 308, 1043-1045.

86. Pilorz, V.; Helfrich-Forster, C.; Oster, H. The role of the circadian clock system in physiology. Pflugers Arch. 2018, 470, 227-239.

87. Hodzic, A.; Lavtar, P.; Ristanovic, M.; Novakovic, I.; Dotlic, J.; Peterlin, B. Genetic variation in the CLOCK gene is associated with idiopathic recurrent spontaneous abortion. PLoS ONE 2018, 13, e0196345.

88. Semenova, N.; Madaeva, I.; Bairova, T.; Kolesnikov, S.; Kolesnikova, L. Lipid peroxidation depends on the clock 3111T/C gene polymorphism in menopausal women with Insomnia. Chronobiol. Int. 2019, 36, 1399-1408.

89. Semenova, N.V.; Madaeva, I.M.; Bairova, T.A.; Zhambalova, R.M.; Sholokhov, L.F.; Kolesnikova, L.I. Association of the melatonin circadian rhythms with clock $3111 \mathrm{~T} / \mathrm{C}$ gene polymorphism in Caucasian and Asian menopausal women with insomnia. Chronobiol. Int. 2018, 35, 1066-1076.

90. Semenova, N.V.; Madaeva, I.M.; Bairova, T.I.; Ershova, O.A.; Kalyuzhnaya, O.V.; Korytov, L.I.; Kolesnikova, L. 3111T/C Clock Gene Polymorphism in Women with Insomnia. Bull. Exp. Biol. Med. 2017, 163, 461-464.

91. Bao, J.; Tang, C.; Li, J.; Zhang, Y.; Bhetwal, B.P.; Zheng, H.; Yan, W. RAN-binding protein 9 is involved in alternative splicing and is critical for male germ cell development and male fertility. PLoS Genet. 2014, 10, e1004825.

92. Yang, J.; Zhang, Z.; Zhang, Y.; Zheng, X.; Lu, Y.; Tao, D.; Liu, Y.; Ma, Y. CLOCK interacts with RANBP9 and is involved in alternative splicing in spermatogenesis. Gene 2018, 642, 199-204.

93. Nicholas, B.; Rudrasingham, V.; Nash, S.; Kirov, G.; Owen, M.J.; Wimpory, D.C. Association of Per1 and Npas2 with autistic disorder: Support for the clock genes/social timing hypothesis. Mol. Psychiatry 2007, 12, 581-592.

94. Kovanen, L.; Saarikoski, S.T.; Aromaa, A.; Lonnqvist, J.; Partonen, T. ARNTL (BMAL1) and NPAS2 gene variants contribute to fertility and seasonality. PLOS ONE 2010, 5, e10007.

95. Boden, M.J.; Varcoe, T.J.; Kennaway, D.J. Circadian regulation of reproduction: From gamete to offspring. Prog. Biophys. Mol. Biol. 2013, 113, 387-397.

96. Liu, Y.; Johnson, B.P.; Shen, A.L.; Wallisser, J.A.; Krentz, K.J.; Moran, S.M.; Sullivan, R.; Glover, E.; Parlow, A.F.; Drinkwater, N.R.; et al. Loss of BMAL1 in ovarian steroidogenic cells results in implantation failure in female mice. Proc. Natl. Acad. Sci. USA 2014, 111, 14295-14300.

97. Xu, J.; Li, Y.; Wang, Y.; Xu, Y.; Zhou, C. Loss of Bmal1 decreases oocyte fertilization, early embryo development and implantation potential in female mice. Zygote 2016, 24, 760-767.

98. Papacleovoulou, G.; Nikolova, V.; Oduwole, O.; Chambers, J.; Vazquez-Lopez, M.; Jansen, E.; Nicolaides, K.; Parker, M.; Williamson, C. Gestational disruptions in metabolic rhythmicity of the liver, muscle, and placenta affect fetal size. FASEB J. 2017, 31, 1698-1708.

99. Mereness, A.L.; Murphy, Z.C.; Forrestel, A.C.; Butler, S.; Ko, C.; Richards, J.S.; Sellix, M.T. Conditional Deletion of Bmal1 in Ovarian Theca Cells Disrupts Ovulation in Female Mice. Endocrinology 2016, 157, 913-927.

100. Green, C.B. Many paths to preserve the body clock. Science 2019, 363, 124-125.

101. Baggs, J.E.; Green, C.B. Nocturnin, a deadenylase in Xenopus laevis retina: A mechanism for posttranscriptional control of circadian-related mRNA. Curr. Biol. 2003, 13, 189-198.

102. Costa-Rodriguez, V.A.; de Groot, M.H.M.; Rijo-Ferreira, F.; Green, C.B.; Takahashi, J.S. Mice under Caloric Restriction Self-Impose a Temporal Restriction of Food Intake as Revealed by an Automated Feeder System. Cell Metab. 2017, 26, 267-277.

103. Le, P.T.; Bornstein, S.A.; Motyl, K.J.; Tian, L.; Stubblefield, J.J.; Hong, H.K.; Takahashi, J.S.; Green, C.B.; Rosen, C.J.; Guntur, A.R. A novel mouse model overexpressing Nocturnin results in decreased fat mass in male mice. J. Cell Physiol. 2019, 234, 20228-20239.

104. Nishikawa, S.; Hatanaka, Y.; Tokoro, M.; Shin, S.W.; Shimizu, N.; Nishihara, T.; Kato, R.; Takemoto, A.; Amano, T.; Anzai, M.; et al. Functional analysis of nocturnin, a circadian deadenylase, at maternal-to-zygotic transition in mice. J. Reprod. Dev. 2013, 59, 258-265. 
105. Kawai, M.; Green, C.B.; Lecka-Czernik, B.; Douris, N.; Gilbert, M.R.; Kojima, S.; Ackert-Bicknell, C.; Garg, N.; Horowitz, M.C.; Adamo, M.L.; et al. A circadian-regulated gene, Nocturnin, promotes adipogenesis by stimulating PPAR-gamma nuclear translocation. Proc. Natl. Acad. Sci. USA 2010, 107, 10508-10513.

106. Cedernaes, J.; Waldeck, N.; Bass, J. Neurogenetic basis for circadian regulation of metabolism by the hypothalamus. Genes Dev. 2019, 33, 1136-1158.

107. Cox, K.H.; Takahashi, J.S. Circadian clock genes and the transcriptional architecture of the clock mechanism. J. Mol. Endocrinol. 2019, 63, R93-R102.

108. Zatorre, R.J.; Fields, R.D.; Johansen-Berg, H. Plasticity in gray and white: Neuroimaging changes in brain structure during learning. Nat. Neurosci. 2012, 15, 528-536.

109. Zeltser, L.M.; Seeley, R.J.; Tschop, M.H. Synaptic plasticity in neuronal circuits regulating energy balance. Nat. Neurosci. 2012, 15, 1336-1342.

110. Jensen, E.C.; Bennet, L.; Guild, S.J.; Booth, L.C.; Stewart, J.; Gunn, A.J. The role of the neural sympathetic and parasympathetic systems in diurnal and sleep state-related cardiovascular rhythms in the late-gestation ovine fetus. Am. J. Physiol. Regul. Integr. Comp. Physiol. 2009, 297, R998-R1008.

111. Padilla, S.L.; Perez, J.G.; Ben-Hamo, M.; Johnson, C.W.; Sanchez, R.E.A.; Bussi, I.; Palmiter, R.D.; de la Iglesia, H.O. Kisspeptin Neurons in the Arcuate Nucleus of the Hypothalamus Orchestrate Circadian Rhythms and Metabolism. Curr. Biol. 2019, 29, 592-604.

112. Mayer, C.; Boehm, U. Female reproductive maturation in the absence of kisspeptin/GPR54 signaling. Nat. Neurosci. 2011, 14, 704-710.

113. Hu, K.L.; Zhao, H.; Yu, Y.; Li, R. Kisspeptin as a potential biomarker throughout pregnancy. Eur. J. Obstet. Gynecol. Reprod. Biol. 2019, 240, 261-266.

114. Tolson, K.P.; Garcia, C.; Yen, S.; Simonds, S.; Stefanidis, A.; Lawrence, A.; Smith, J.T.; Kauffman, A.S. Impaired kisspeptin signaling decreases metabolism and promotes glucose intolerance and obesity. J. Clin. Invest. 2014, 124, 3075-3079.

115. Mittelman-Smith, M.A.; Krajewski-Hall, S.J.; McMullen, N.T.; Rance, N.E. Ablation of KNDy Neurons Results in Hypogonadotropic Hypogonadism and Amplifies the Steroid-Induced LH Surge in Female Rats. Endocrinology 2016, 157, 2015-2027.

116. De Pedro, M.A.; Moran, J.; Diaz, I.; Murias, L.; Fernandez-Plaza, C.; Gonzalez, C.; Diaz, E. Circadian Kisspeptin expression in human term placenta. Placenta 2015, 36, 1337-1339.

117. Padilla, S.L.; Qiu, J.; Nestor, C.C.; Zhang, C.; Smith, A.W.; Whiddon, B.B.; Ronnekleiv, O.K.; Kelly, M.J.; Palmiter, R.D. AgRP to Kiss1 neuron signaling links nutritional state and fertility. Proc. Natl. Acad. Sci. USA 2017, 114, 2413-2418.

118. Reiter, R.J.; Tamura, H.; Tan, D.X.; Xu, X.Y. Melatonin and the circadian system, Contributions to successful female reproduction. Fertil Steril 2014, 102, 321-328.

119. Tamura, H.; Nakamura, Y.; Terron, M.P.; Flores, L.J.; Manchester, L.C.; Tan, D.X.; Sugino, N.; Reiter, R.J. Melatonin and pregnancy in the human. Reprod. Toxicol. 2008, 25, 291-303.

120. Martin-Fairey, C.A.; Zhao, P.; Wan, L.; Roenneberg, T.; Fay, J.; Ma, X.; McCarthy, R.; Jungheim, E.S.; England, S.K.; Herzog, E.D. Pregnancy Induces an Earlier Chronotype in Both Mice and Women. J. Biol. Rhythm. 2019, 34, 323-331.

121. McCarthy, R.; Jungheim, E.S.; Fay, J.C.; Bates, K.; Herzog, E.D.; England, S.K. Riding the Rhythm of Melatonin Through Pregnancy to Deliver on Time. Front. Endocrinol. (Lausanne) 2019, 10, 616.

122. Reiter, R.J.; Tan, D.X.; Tamura, H.; Cruz, M.H.; Fuentes-Broto, L. Clinical relevance of melatonin in ovarian and placental physiology: A review. Gynecol. Endocrinol. 2014, 30, 83-89.

123. Voiculescu, S.E.; Zygouropoulos, N.; Zahiu, C.D.; Zagrean, A.M. Role of melatonin in embryo fetal development. J. Med. Life 2014, 7, 488-492.

124. Mahoney, M.M. Shift work, jet lag, and female reproduction. Int. J. Endocrinol. 2010, 2010, 813764.

125. Fernando, S.; Biggs, S.N.; Horne, R.S.C.; Vollenhoven, B.; Lolatgis, N.; Hope, N.; Wong, M.; Lawrence, M.; Lawrence, A.; Russell, C.; et al. The impact of melatonin on the sleep patterns of women undergoing IVF: A double blind RCT. Hum. Reprod. Open 2017, 2017, hox027.

126. Torres-Farfan, C.; Richter, H.G.; Germain, A.M.; Valenzuela, G.J.; Campino, C.; Rojas-Garcia, P.; Forcelledo, M.L.; Torrealba, F.; Seron-Ferre, M. Maternal melatonin selectively inhibits cortisol production in the primate fetal adrenal gland. J. Physiol. 2004, 554, 841-856. 
127. Valenzuela, F.J.; Torres-Farfan, C.; Richter, H.G.; Mendez, N.; Campino, C.; Torrealba, F.; Valenzuela, G.J.; Seron-Ferre, M. Clock gene expression in adult primate suprachiasmatic nuclei and adrenal: Is the adrenal a peripheral clock responsive to melatonin? Endocrinology 2008, 149, 1454-1461.

128. Zhang, L.; Zhang, Z.; Wang, F.; Tian, X.; Ji, P.; Liu, G. Effects of melatonin administration on embryo implantation and offspring growth in mice under different schedules of photoperiodic exposure. Reprod. Biol. Endocrinol. 2017, 15, 78.

129. Eckel, L.A. The ovarian hormone estradiol plays a crucial role in the control of food intake in females. Physiol. Behav. 2011, 104, 517-524.

130. Zhu, L.; Zou, F.; Yang, Y.; Xu, P.; Saito, K.; Othrell, H.A., Jr.; Yan, X.; Ding, H.; Wu, Q.; Fukuda, M.; et al. Estrogens prevent metabolic dysfunctions induced by circadian disruptions in female mice. Endocrinology 2015, 156, 2114-2123.

131. Gery, S.; Virk, R.K.; Chumakov, K.; Yu, A.; Koeffler, H.P. The clock gene Per2 links the circadian system to the estrogen receptor. Oncogene 2007, 26, 7916-7920.

132. Nakamura, T.J.; Sellix, M.T.; Menaker, M.; Block, G.D. Estrogen directly modulates circadian rhythms of PER2 expression in the uterus. Am. J. Physiol. Endocrinol. Metab. 2008, 295, E1025-E1031.

133. Xu, Y.; Nedungadi, T.P.; Zhu, L.; Sobhani, N.; Irani, B.G.; Davis, K.E.; Zhang, X.; Zou, F.; Gent, L.M.; Hahner, L.D.; et al. Distinct hypothalamic neurons mediate estrogenic effects on energy homeostasis and reproduction. Cell Metab. 2011, 14, 453-465.

134. Kotani, K.; Tokunaga, K.; Fujioka, S.; Kobatake, T.; Keno, Y.; Yoshida, S.; Shimomura, I.; Tarui, S.; Matsuzawa, Y. Sexual dimorphism of age-related changes in whole-body fat distribution in the obese. Int. J. Obes. Relat. Metab. Disord. 1994, 18, 207-202.

135. Bauer, C.R.; Lambert, B.L.; Bann, C.M.; Lester, B.M.; Shankaran, S.; Bada, H.S.; Whitaker, T.M.; Lagasse, L.L.; Hammond, J.; Higgins, R.D. Long-term impact of maternal substance use during pregnancy and extrauterine environmental adversity: Stress hormone levels of preadolescent children. Pediatr. Res. 2011, 70, $213-219$.

136. Iwata, O.; Okamura, H.; Saitsu, H.; Saikusa, M.; Kanda, H.; Eshima, N.; Iwata, S.; Maeno, Y.; Matsuishi, T. Diurnal cortisol changes in newborn infants suggesting entrainment of peripheral circadian clock in utero and at birth. J. Clin. Endocrinol. Metab. 2013, 98, E25-E32.

137. Redman, L.M.; Ravussin, E. Caloric restriction in humans: Impact on physiological, psychological, and behavioral outcomes. Antioxid. Redox. Signal. 2011, 14, 275-287.

138. Manoogian, E.N.C.; Panda, S. Circadian rhythms, time-restricted feeding, and healthy aging. Ageing Res. Rev. 2017, 39, 59-67.

139. Panda, S. The arrival of circadian medicine. Nat. Rev. Endocrinol. 2019, 15, 67-69.

140. Li, S.W.; Yu, H.R.; Sheen, J.M.; Tiao, M.M.; Tain, Y.L.; Lin, I.C.; Lin, Y.J.; Chang, K.A.; Tsai, C.C.; Huang, L.T. A maternal high-fat diet during pregnancy and lactation, in addition to a postnatal high-fat diet, leads to metabolic syndrome with spatial learning and memory deficits: Beneficial effects of resveratrol. Oncotarget 2017, 8, 111998-112013.

141. Christians, J.K.; Lennie, K.I.; Wild, L.K.; Garcha, R. Effects of high-fat diets on fetal growth in rodents: A systematic review. Reprod. Biol. Endocrinol. 2019, 17, 39.

142. Lin, Y.J.; Tsai, C.C.; Huang, L.T.; Sheen, J.M.; Tiao, M.M.; Yu, H.R.; Chen, C.C.; Tain, Y.L. Detrimental effect of maternal and post-weaning high-fat diet on the reproductive function in the adult female offspring rat: Roles of insulin-like growth factor 2 and the ovarian circadian clock. J. Assist. Reprod. Genet. 2017, 34, 817-826.

143. Akle, V.; Stankiewicz, A.J.; Kharchenko, V.; Yu, L.; Kharchenko, P.V.; Zhdanova, I.V. Circadian Kinetics of Cell Cycle Progression in Adult Neurogenic Niches of a Diurnal Vertebrate. J. Neurosci. 2017, 37, 1900-1909.

144. Stankiewicz, A.J.; McGowan, E.M.; Yu, L.; Zhdanova, I.V. Impaired Sleep, Circadian Rhythms and Neurogenesis in Diet-Induced Premature Aging. Int. J. Mol. Sci. 2017, 18, 2243.

145. Kohsaka, A.; Laposky, A.D.; Ramsey, K.M.; Estrada, C.; Joshu, C.; Kobayashi, Y.; Kobayashi, Y.; Turek, F.W.; Bass, J. High-fat diet disrupts behavioral and molecular circadian rhythms in mice. Cell Metab. 2007, $6,414-421$.

146. Hatori, M.; Vollmers, C.; Zarrinpar, A.; DiTacchio, L.; Bushong, E.A.; Gill, S.; Leblanc, M.; Chaix, A.; Joens, M.; Fitzpatrick, J.A.; et al. Time-restricted feeding without reducing caloric intake prevents metabolic diseases in mice fed a high-fat diet. Cell Metab. 2012, 15, 848-860.

147. Chaix, A.; Zarrinpar, A.; Miu, P.; Panda, S. Time-restricted feeding is a preventative and therapeutic intervention against diverse nutritional challenges. Cell Metab. 2014, 20, 991-1005. 
148. Chaix, A.; Lin, T.; Le, H.D.; Chang, M.W.; Panda, S. Time-Restricted Feeding Prevents Obesity and Metabolic Syndrome in Mice Lacking a Circadian Clock. Cell Metab. 2018, 29, 303-319.

149. Pan, X.; Zhang, Y.; Wang, L.; Hussain, M.M. Diurnal regulation of MTP and plasma triglyceride by CLOCK is mediated by SHP. Cell Metab. 2010, 12, 174-186.

150. Raabe, M.; Flynn, L.M.; Zlot, C.H.; Wong, J.S.; Veniant, M.M.; Hamilton, R.L.; Young, S.G. Knockout of the abetalipoproteinemia gene in mice: Reduced lipoprotein secretion in heterozygotes and embryonic lethality in homozygotes. Proc. Natl. Acad. Sci. USA 1998, 95, 8686-8691.

151. Chaix, A.; Manoogian, E.N.C.; Melkani, G.C.; Panda, S. Time-Restricted Eating to Prevent and Manage Chronic Metabolic Diseases. Annu. Rev. Nutr. 2019, 39, 291-315.

152. Longo, V.D.; Panda, S. Fasting, Circadian Rhythms, and Time-Restricted Feeding in Healthy Lifespan. Cell Metab. 2016, 23, 1048-1059.

153. Manoogian, E.N.C.; Chaix, A.; Panda, S. When to Eat: The Importance of Eating Patterns in Health and Disease. J. Biol. Rhythm. 2019. [CrossRef]

154. I'Anson, H.; Foster, D.L.; Foxcroft, G.R.; Booth, P.J. Nutrition and reproduction. Oxf. Rev. Reprod. Biol. 1991, 13, 239-311.

155. Booth, P.J.; Cosgrove, J.R.; Foxcroft, G.R. Endocrine and metabolic responses to realimentation in feed-restricted prepubertal gilts: Associations among gonadotropins, metabolic hormones, glucose, and uteroovarian development. J. Anim. Sci. 1996, 74, 840-848.

156. Kumar, S.; Kaur, G. Intermittent fasting dietary restriction regimen negatively influences reproduction in young rats: A study of hypothalamo-hypophysial-gonadal axis. PLoS ONE 2013, 8, e52416.

157. Archer, Z.A.; Rhind, S.M.; Findlay, P.A.; Kyle, C.E.; Barber, M.C.; Adam, C.L. Hypothalamic responses to peripheral glucose infusion in food-restricted sheep are influenced by photoperiod. J. Endocrinol. 2005, 184, 515-525.

158. Archer, Z.A.; Findlay, P.A.; McMillen, S.R.; Rhind, S.M.; Adam, C.L. Effects of nutritional status and gonadal steroids on expression of appetite-regulatory genes in the hypothalamic arcuate nucleus of sheep. J. Endocrinol. 2004, 182, 409-419.

159. Nagatani, S.; Thompson, R.C.; Foster, D.L. Prevention of glucoprivic stimulation of corticosterone secretion by leptin does not restore high frequency luteinizing hormone pulses in rats. J. Neuroendocrinol. 2001, 13, 371-377.

160. Swamy, S.; Xie, X.; Kukino, A.; Calcagno, H.E.; Lasarev, M.R.; Park, J.H.; Butler, M.P. Circadian disruption of food availability significantly reduces reproductive success in mice. Horm. Behav. 2018, 105, 177-184.

161. Novakova, M.; Sladek, M.; Sumova, A. Exposure of pregnant rats to restricted feeding schedule synchronizes the SCN clocks of their fetuses under constant light but not under a light-dark regime. J. Biol. Rhythm. 2010, 25, 350-360.

162. Pan, X.; Munshi, M.K.; Iqbal, J.; Queiroz, J.; Sirwi, A.A.; Shah, S.; Younus, A.; Hussain, M.M. Circadian regulation of intestinal lipid absorption by apolipoprotein AIV involves forkhead transcription factors A2 and $\mathrm{O} 1$ and microsomal triglyceride transfer protein. J. Biol. Chem. 2013, 288, 20464-20476.

163. Pan, X.; Hussain, M.M. Diurnal regulation of microsomal triglyceride transfer protein and plasma lipid levels. J. Biol. Chem. 2007, 282, 24707-24719.

164. Yao, Y.; Lu, S.; Huang, Y.; Beeman-Black, C.C.; Lu, R.; Pan, X.; Hussain, M.M.; Black, D.D. Regulation of microsomal triglyceride transfer protein by apolipoprotein A-IV in newborn swine intestinal epithelial cells. Am. J. Physiol. Gastrointest. Liver Physiol. 2011, 300, G357-G363.

(C) 2020 by the authors. Licensee MDPI, Basel, Switzerland. This article is an open access article distributed under the terms and conditions of the Creative Commons Attribution (CC BY) license (http://creativecommons.org/licenses/by/4.0/). 